\title{
Predictive factors of lethality and complications of deep fascial space infections of the neck
}

\section{Fatores preditivos de letalidade e complicações das infecções dos espaços fasciais profundos do pescoço}

Alexandre Baba Suehara ${ }^{1}$ iD; André Afonso Nimitz Rodrigues ${ }^{2}$; Norberto Kodi Kavabata ${ }^{1}$; Marcelo Benedito Menezes, TCBC-SP1; Evelyn de Almeida Ramos 3 ; Julia Nascimento Kawamukai; Antonio José Gonçalves, TCBC-SP1.

\section{A B S T R A C T}

\begin{abstract}
Objective: to identify predictive factors for lethality and complications of deep fascial space infections of the neck (DFSIN), establishing an early and aggressive treatment in the neck before the progression to descending mediastinitis. Methods: we retrospectively analyzed 133 cases of DFSIN treated at Discipline of Head and Neck Surgery of the Medicine School of Santa Casa de Misericórdia de São Paulo. We accessed demographic characteristics, associated diseases, clinical presentation, laboratorial tests, length of hospital stay, number of involved anatomic neck spaces, intra-operative and microbiology findings. We analyzed these data using logistic regression to predict DFSIN lethality and life threatening complications (mediastinitis, septic shock, pneumonia, pleural empyema, skin necrosis). Results: lethality and complication ratios were $9 \%$ and $50.3 \%$, respectively. The logistic regression model showed that patients with septic shock were more likely to have progression to death $(p<0.001)$ and, the presence of more than two involved neck spaces $(p<0.001)$ and older individuals $(p=0.017)$ were more likely to have complicated deep neck infections. Descending necrotizing mediatinitis increased the lethality ratio by $50 \%$, and was associated to necrotizing fasciitis $(\mathrm{p}=0.012)$ and pleural empyema $(\mathrm{p}<0.001)$. Conclusion: septic shock is a lethal predictive factor and age as well as more than two involved neck spaces are the predictive factors for complications. Necrotizing fasciitis is an important factor for complications and death. Therefore, its surgical treatment must be more aggressive. Descending mediastinitis has a high lethal rate and the successful treatment is based on early diagnosis and aggressive surgical approach.
\end{abstract}

Keywords: Infection. Neck. Necrotizing Fasciitis. Mortality. Mediastinitis.

\section{INTRODUCTION}

D eep fascial space infections of the neck (DFSIN) are diseases of bacterial etiology that affect the potential spaces and fascial planes of the neck. They may present with or without purulent formation. They are often confused, from a clinical point of view, with the term "cervical abscess". In this condition, we should note, there is no fluctuation, a typical signal of the abscess, but a firm neck bulging and induration ${ }^{1-4}$. They most often result from neck spread of dental and oropharyngeal infections ${ }^{5}$.

The severity of this infection refers to the risk of spreading, through these spaces and fascial planes, to the mediastinum, especially the posterior one, producing necrotizing descending mediastinitis ${ }^{6}$, whose lethality rate varies between $17.5 \%$ and $50 \%{ }^{3,6}$. In addition, other complications may occur, namely: septic shock, pleural empyema, airway obstruction, pericarditis, pericardial effusion, jugular vein thrombosis, septic embolism, acute renal failure, respiratory distress syndrome, brain abscesses, and disseminated intravascular coagulation ${ }^{7-9}$.

Despite the reduction of incidence due to the use of antibiotics, improvement in dental care and the technological advance in intensive care units, DFSIN have currently high rates of morbidity and mortality, especially when the patient evolves to descending necrotizing mediastinitis. In part, delay in the correct diagnosis of

1 - Faculdade de Ciências Médicas da Santa Casa de São Paulo, Departamento de Cirurgia, Disciplina de Cirurgia de Cabeça e Pescoço - São Paulo SP - Brasil 2 - Faculdade de Medicina de Jundiaí, Disciplina de Cirurgia de Cabeça e Pescoço - Jundiaí - SP - Brasil 3 - Faculdade de Ciências Médicas da Santa Casa de São Paulo, acadêmica - São Paulo - SP - Brasil 
DFSIN postpones appropriate treatment, allowing the progression, sometimes fast, to serious complications and death. However, certain clinical and radiological characteristics of the patient and the circumstances of treatment may predispose to the development of these complications, such as associated systemic disease, especially diabetes mellitus ${ }^{10}$, respiratory failure ${ }^{11}$, involvement of more than two neck fascial spaces, delay in the appropriate treatment, edema in the neck or cervical bulging ${ }^{7}$, and advanced age ${ }^{12}$.

The objective of this study is to identify predictive factors for DFSIN poor evolution (lethality and complications), allowing the establishment of an appropriate treatment for this infection before the onset of complications, thus reducing morbidity and mortality rates.

\section{METHODS}

This is a retrospective study, using data from medical records at the Medical and Statistical Archive Service (SAME) of the Central Hospital of Irmandade da Santa Casa de Misericórdia de São Paulo. We obtained the approval of the Human Ethics in Research Committee, with project number 224/05.

Inclusion criteria for the study: patients with infections that affected the fasciae and potential deep neck spaces, with indication for surgical treatment.

Exclusion criteria for the study: patients with head and neck tumors and in the postoperative period of elective head and neck surgery.

We studied 138 patients with deep cervical infection who underwent surgical treatment in the Head and Neck Surgery Discipline, admitted to the Emergency Service of the Central Hospital of the Faculty of Medical Sciences of the Santa Casa de Misericórdia de São Paulo (FCMSCSP), between June 1997 and January 2006. In compliance with the eligibility criteria for the research, we excluded five patients from the study. One patient had a superficial infection of an elective surgical wound, treated with drainage under local anesthesia; one had been treated in another service and with incomplete medical record data; two patients were treated only with antibiotic therapy; and one individual had advanced oral cavity squamous cell carcinoma. We then included 133 patients in the study.

Demographic data was collected (age, sex and race), as well as social habits and addictions, including smoking, alcohol consumption and use of illicit drugs, and associated diseases. We also collected clinical and laboratory data, namely: clinical presentation of the disease, etiology, hematological and electrolyte tests, bacteriology, treatment and complications. We determined the neck spaces affected by the infection through the evaluation of contrast computed tomography and by the intraoperative findings described in the surgical reports. We calculated the lethality and the complication rates.

We performed the statistical analysis using the SPSS (O) 2017, version 25.0, using nonparametric tests for data modeling and selection of variables for the logistic regression model, in order to identify the factors that could be associated with lethality and increased infection severity. We defined two dependent variables: death and complications. We considered complicated cases those of patients who presented with one or more of the following complications: descending mediastinitis, septic shock, pleural empyema, pneumonia and skin necrosis. We used the Student's t test for univariate analysis for normal continuous dependent variables, and the MannWhitney tests for non-normal continuous dependent variables. We applied the Chi square and Fisher tests for binary or categorical dependent variables. Finally, for the multivariate analysis we used the logistic regression as a method to identify variables that were associated with lethality and complications. Statistical significance was set at $p<0.05$.

\section{RESULTS}

Of the 133 patients analyzed, 84 were male (63.2\%). The average age was 36.4 years. Smoking was reported by 32 patients, and the consumption of alcohol, by 17. Four patients reported the use of illicit drugs, namely: one user of Cannabis sativa (marijuana), one of inhaled cocaine, and two who used intravenous drugs (Table 1).

Thirty-eight patients were diabetic, 19 had hypertension, 10 had heart disease, four had lung disease, eight had malignant neoplasia, three had 
HIV, two had liver cirrhosis, seven had hepatitis B, one had Lupus, two had kidney disease, and two had neutropenia.

The most common origin of DFSIN was dental $(33.6 \%)$, followed by tonsillar $(23.9 \%)$, skin and parotid infection (6.0\%), submandibular gland (3.7\%), and trauma (3.0\%). In 23 patients (17.2\%), the cause was not determined. Other causes (6.7\%) were infected lymph node in five patients, infected ganglionic tuberculosis in one, central catheter-related infection in one, and one otitis media complicated with suppurative mastoiditis (Table 1).

\section{Clinical presentation}

Table 1. Patients' characteristics ( $n=133)$.

\begin{tabular}{lc}
\hline $\begin{array}{l}\text { Age (years), mean } \pm \text { standard } \\
\text { deviation }\end{array}$ & $36.4 \pm 17.7$ \\
Sex** & \\
Male & $84(63.2 \%)$ \\
Female & $49(36.8 \%)$ \\
Social habits and addictions ** & \\
Smoking & $32(24.1 \%)$ \\
Ethics & $17(12.8 \%)$ \\
Marijuana & $1(0.8 \%)$ \\
Inhaled Cocaine & $1(0.8 \%)$ \\
Intravenous drugs & $2(1.5 \%)$ \\
Comorbidities ** & \\
Diabetes mellitus & $38(28.6 \%)$ \\
Arterial hypertension & $19(14.3 \%)$ \\
Heart disease & $10(7.5 \%)$ \\
Cancer* & $8(6 \%)$ \\
Hepatitis B & $7(5.3 \%)$ \\
HIV positive & $3(2.3 \%)$ \\
Pneumopathy & $4(3 \%)$ \\
Esophageal varices & $2(1.5 \%)$ \\
Neutropenia & $2(1.5 \%)$ \\
Nephropathy & $2(1.5 \%)$ \\
Hepatic cirrhosis & $2(1.5 \%)$ \\
Lupus & $1(0.8 \%)$ \\
Denology** & \\
Tonsil & $45(33.8 \%)$ \\
Unknown & $32(24.1 \%)$ \\
\hline & $23(17.3 \%)$ \\
\hline
\end{tabular}

\begin{tabular}{lc}
\hline Parotid & $8(6,0 \%)$ \\
Skin & $8(6,0 \%)$ \\
Submandibular Gland & $5(3.8 \%)$ \\
Trauma & $4(3,0 \%)$ \\
Others & $8(6,0 \%)$ \\
\hline${ }^{*}$ malignant neoplasm of head and neck, ${ }^{* *}$ absolute frequency (relative \\
frequency).
\end{tabular}

Most of the signs and symptoms of DFSIN occurred concomitantly, with more frequently manifestations being local pain, increased neck volume, fever, and neck cutaneous hyperemia (Table 1).

The average interval between the onset of symptoms and admission to the emergency room at this institution was 8.2 days.

Other clinical data $(n=13)$ were palpable cervical lymph nodes $(n=1)$, otalgia $(n=2)$, chest pain $(n=2)$, periorbital edema $(n=2)$, purulent otorrhea $(n$ $=1)$, vomiting and diarrhea and $(n=1)$, dyspnea $(n=1)$, laryngeal deviation $(n=1)$, headache $(n=1)$, and parotid swelling $(n=1)$.

\section{Surgical treatment and intraoperative findings \\ One hundred and thirty-two patients underwent} surgical treatment. One patient was not operated due to serious illness, secondary to descending mediastinitis, dying soon after admission. Of the 132 operated patients, 43 required more than one procedure. Ninetyseven patients underwent exclusive cervicotomy and, in six, the cervicotomy was performed with debridement of devitalized tissues (Table 2).

The site of infection is described in table 2 . The involvement of more than two anatomical spaces occurred in 106 patients and, in 27, three or more spaces were involved. Thirty patients had bilateral involvement of the cervical spaces.

Table 2 also shows isolated infectious agents. Of the 132 operated patients, 60 had positive cultures, of which 48 (80\%) with an isolated agent, seven (11.6\%) with two, and five (8.3\%) with three isolated agents. The most commonly isolated bacterium was Staphylococcus aureus, in 25 patients (41.7\%), followed by Streptococcus viridans, in seven (11.7\%). Results of 47 cultures (35.6\%) 
were negative and 25 cultures (18.9\%) were not identified in medical records.

Table 2. Procedures performed, intraoperative findings, spaces involved and microbiology.

\begin{tabular}{|c|c|c|}
\hline \multirow{2}{*}{\multicolumn{2}{|c|}{ Procedures performed }} & \multirow[b]{2}{*}{$\%(n=132)$} \\
\hline & & \\
\hline Cervicotomy & 97 & $72.9 \%$ \\
\hline Cervicotomy + tracheostomy & 20 & $15.0 \%$ \\
\hline Cervicotomy + thoracotomy & 13 & $9.8 \%$ \\
\hline Cervicotomy + pleural drainage & 6 & $4.5 \%$ \\
\hline Cervicotomy + mastoidectomy & 1 & $0.8 \%$ \\
\hline Intraoperative findings & & $\%(n=132)$ \\
\hline Pus & 98 & $74.2 \%$ \\
\hline Necrotizing fasciitis + pus & 20 & $15.2 \%$ \\
\hline Fasciitis without pus & 11 & $8.3 \%$ \\
\hline Necrotizing fasciitis & 3 & $2.3 \%$ \\
\hline $\begin{array}{l}\text { Frequency of involved neck spaces by } \\
\text { infection }\end{array}$ & & $\%(n=133)$ \\
\hline Submandibular & 102 & $76.7 \%$ \\
\hline Parapharyngeal & 76 & $57.1 \%$ \\
\hline Upper mediastinum & 23 & $17.3 \%$ \\
\hline Pleural & 18 & $13.5 \%$ \\
\hline Lower mediastinum & 14 & $10.5 \%$ \\
\hline Retropharyngeal & 9 & $6.8 \%$ \\
\hline Parotid & 9 & $6.8 \%$ \\
\hline Superficial & 7 & $5.3 \%$ \\
\hline Pericardial & 3 & $2.3 \%$ \\
\hline Pre-tracheal & 2 & $1.5 \%$ \\
\hline \multicolumn{3}{|l|}{ Bacteria identified in 60 positive cultures } \\
\hline Gram Positive & & $\%(n=60)$ \\
\hline Staphylococcus aureus & 25 & $41.7 \%$ \\
\hline Streptococcus viridans & 7 & $11.7 \%$ \\
\hline $\begin{array}{l}\beta \text { Hemolytic non-A and non-B } \\
\text { streptococcus }\end{array}$ & 6 & $10.0 \%$ \\
\hline $\begin{array}{l}\text { Non-enteroccocus group D } \\
\text { Streptococcus }\end{array}$ & 5 & $8.3 \%$ \\
\hline Streptococcus pneumoniae & 3 & $5.0 \%$ \\
\hline Coagulase negative Staphylococcus & 3 & $5.0 \%$ \\
\hline Enterococcus sp & 3 & $5.0 \%$ \\
\hline Streptococcus pyogenes & 2 & $3.3 \%$ \\
\hline Group G streptococcus & 1 & $1.7 \%$ \\
\hline Gamma-Hemolytic Streptococcus & 1 & $1.7 \%$ \\
\hline
\end{tabular}

\begin{tabular}{lll}
\hline Gram Negatives & & \\
Pseudomonas aeruginosa & 3 & $5.0 \%$ \\
Klebsiella pneumoniae & 2 & $3.3 \%$ \\
Enterobacter sp & 2 & $3.3 \%$ \\
Acinetobacter baumanii & 1 & $1.7 \%$ \\
Proteus mirabilis & 1 & $1.7 \%$ \\
Klebsiella oxytoca & 1 & $1.7 \%$ \\
Citrobacter freundii & 1 & $1.7 \%$ \\
Morganela morganii & 1 & $1.7 \%$ \\
Stenotrophomonas maltophilia & 1 & $1.7 \%$ \\
Providencia rettgeri & 1 & $1.7 \%$ \\
Neisseira sp & 1 & $1.7 \%$ \\
Anaerobes & & \\
Bacterioides sp & 3 & $5.0 \%$ \\
Peptostreptococcus species & 2 & $3.3 \%$ \\
\hline
\end{tabular}

\section{Complications and lethality of deep neck infections}

Sixty-seven (50.3\%) patients presented the complications shown in table 3 . The most serious complication was descending necrotizing mediastinitis, observed in 14 patients, of whom seven survived.

Lethality rate was a $9 \%(n=12)$. Of the 12 individuals who died, seven were men and five were women. Five were diabetics, three had chronic hypertension, four had malignant neoplasms (bone marrow aplasia, colon cancer undergoing chemotherapy, gastric cancer, lymphoma), one had alcoholic cirrhosis and esophageal varices, one had lupus nephritis, and one, hepatitis $B$. The most common infection etiology in these cases was dental $(n=6)$, followed by tonsillar $(n=$ $3)$, two of unknown cause, and one of skin origin. Nine patients died from septic shock refractory to therapeutic measures, one due to pulmonary thromboembolism, one due to hemorrhagic shock due to bleeding from esophageal varices, and one due to malfunction of a cardiac pacemaker.

Six patients were reoperated. Two needed new cervical drainage; three, in addition to new cervical drainage, needed a thoracotomy, and one, surgical debridement. 
Table 3. Complications of cervical infections in 67 patients.

\begin{tabular}{lcc}
\hline & $n$ & $\%(n=67)$ \\
\hline Compromised airway & 45 & $67.2 \%$ \\
Septic shock & 18 & $26.9 \%$ \\
Pleural empyema & 18 & $26.9 \%$ \\
Descending necrotizing & 14 & $20.9 \%$ \\
mediastinitis & 10 & $14.9 \%$ \\
Pneumonia & 4 & $6.0 \%$ \\
Skin necrosis & 4 & $6.0 \%$ \\
Vocal cord paralysis & 3 & $4.5 \%$ \\
Pericarditis & 2 & $3.0 \%$ \\
Facial paralysis & 2 & $3.0 \%$ \\
Acute pulmonary edema & 1 & $1.5 \%$ \\
Internal jugular vein thrombosis & 1 & $1.5 \%$ \\
Upper gastrointestinal bleeding & 1 & $1.5 \%$ \\
\hline Acute renal failure & & \\
\hline
\end{tabular}

Descending necrotizing mediastinitis occurred in 14 patients, of whom seven (50\%) died. Of these seven, four underwent thoracotomy and, of the seven that survived, all underwent thoracotomy. Of the three patients who did not undergo thoracotomy, one died just after hospital admission, and two underwent neck incision and drainage of the superior mediastinum with delayed diagnosis of descending mediastinitis.

The average length of hospital stay was 12.6 \pm 14.4 days. Patients who presented complications $(n=$ 67) remained, on average, $17.6 \pm 18.6$ days hospitalized, while the uncomplicated ones stayed, on average, 7.6 \pm 3.9 days. Patients who died $(n=12)$ remained, on average, $27 \pm 35.5$ days hospitalized. Surviving patients' mean length of hospital stay was $11.2 \pm 9.4$ days.

Thirty-eight patients $(28.6 \%)$ required admission to the intensive care unit, with an average length of stay of $11.7 \pm 14.5$ days. Ventilatory assistance was used in all these patients, on average for $7.4 \pm 9.1$ days.

In 18 patients, the use of vasoactive drugs was necessary due to the occurrence of septic shock. In these cases, norepinephrine was used. Of the 14 patients with descending mediastinitis, 12 required treatment in the intensive care unit, with an average stay of $17.7 \pm 20.3$ days, and ventilatory assistance, on average, for $11.9 \pm$ 13 days. The remaining two patients, one died just after hospital admission, without minimum clinical conditions for surgery, and other evolved satisfactorily after surgery, without the need for intensive care or vasoactive medication.

The multivariate logistic regression model selected septic shock $(p<0.001)$ as a predictor of death, with an odds ratio of 70.6 (95\% Cl: 13.2-378.5). Thus, patients with septic shock are almost 71 times more likely to die. The probability of a patient dying when presented with septic shock is equal to $55.6 \%$, as also established by the stepwise logistic regression model.

Regarding the risk of complications, the multivariate logistic regression model indicated that the variables associated with complications were age ( $p=$ $0.017)$ and involvement of more than two anatomical neck spaces $(p<0.001)$, in which case the odds ratio was 21.1 (95\% Cl: 7.1 62.7). The graph in figure 1 estimates the probability of complications with the presence of the two selected factors (age and involvement of more than two anatomical spaces).

When analyzing patients with descending necrotizing mediastinitis, the associated variables were necrotizing fasciitis, with OR 15.6 (95\% Cl: 1.9-131.2, p $=0.012)$ and pleural empyema, with OR $116.4(95 \% \mathrm{Cl}$ : $11.1850 .0, p<0.001)$.

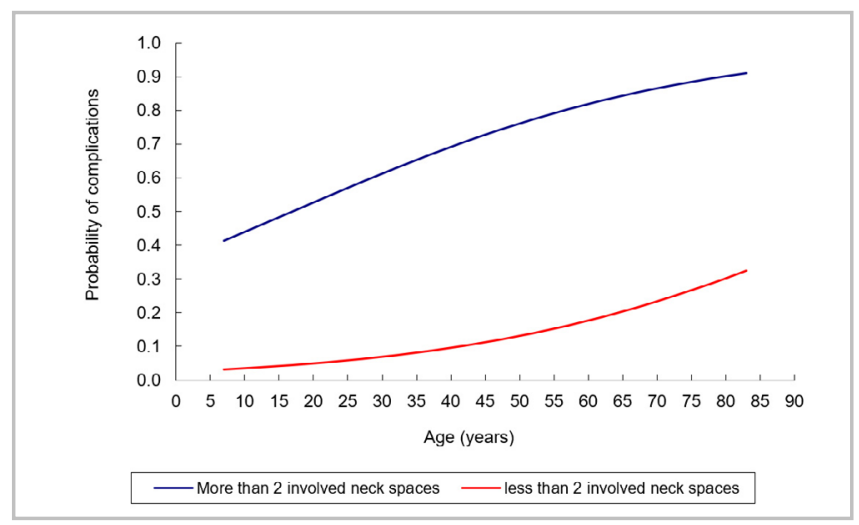

Figure 1. Graphic of logistic regression model for deep neck infection complications

Results of odds ratio calculated by logistic regression model: for more than two involved neck spaces, the value is 21,1 (Cl 95\%: 7,1; 62,7). Thus, a patient with more than 2 involved neck spaces and older has 21 more chances to have complications than a patient with less than two involved neck space. 


\section{DISCUSSION}

Infections of the deep fascial spaces of the neck predominantly affect young adults. The average age reported is 44.5 years $^{13}$, while in this series it was 36.4 years. Males were affected twice as often as females, as reported by Huang et al. ${ }^{14}$ and Marioni et al. ${ }^{12}$. In our series, we observed a 1.7:1 ratio.

In the multivariate analysis, age was a predictor of complications ( $p$ 0.017), the elderly being at higher risk. The negative impact that age has on the prognosis of infections (more complications in the elderly) may be related to the presence of associated comorbidities instead of age itself ${ }^{12}$.

Three large studies emphasize the importance of DFSIN in diabetics, with complication rates varying between $13 \%$ and $33 \%$ and the risk of developing them 3.5 times higher $14,15,17$. The most frequently found comorbidities in this study were diabetes (28.6\%) and hypertension (14.3\%). Due to the small number of complicated cases ( $n=11$ ), we found no difference between non-diabetics and diabetics, although the latter had a high complication rate (37.9\%). We agree that these patients should receive early treatment, associated with a strict control of blood glucose, specially those who are unaware of being diabetic, being important collection of glucose blood sample in all cases.

The authors who studied the predisposing factors with worse DFSIN evolution showed some characteristics of clinical presentation that may be associated with complications, namely cervical bulging, respiratory failure and septic shock $2,4,18$.

In our study, the presence of septic shock, a serious complication of mediastinitis, was statistically significant for risk of death $(p<0.001)$, while pleural effusion was associated with occurrence of complications $(p<0.001)$. In our experience, the presence of septic shock and/or pleural effusion are clinical indications of extreme severity of the infection, and an evolution to mediastinitis should be suspected.

We had a very high complications rate $(50.3 \%)$, while in the literature it varies between $14.5 \%{ }^{19}$ and $18.4 \%^{2}$, mostly associated with lethality. However, when we select only the severe complications (mediastinitis, septic shock, pneumonia, pleural effusion), this rate decreases to $22 \%$. Serious complications frequently cited in the literature are septic shock $2,9,20,21$ (2.6\% 6.15\%), compromised airway ${ }^{9,21}(1.4 \% 7.6 \%)$ and descending necrotizing mediastinitis ${ }^{6,21}$ (3.4\% 18.6\%). In this study, 18 patients (13.5\%) had septic shock, of whom 12 $(67 \%)$ already had mediastinitis. This shows that a high percentage of patients who develop septic shock may have already established mediastinitis. We were unable to determine this relationship in this analysis. However, we identified septic shock as a predictor of death $(p<0.001)$.

Descending necrotizing mediastinitis occurred in 14 patients (11\%). The mean age was $38.71 \pm 15.14$ years. Seven were male. Four were diabetic, two had malignancy and one had lupus. Factors that could predict mediastinitis were the presence of pleural empyema ( $p$ $<0.001)$ and necrotizing fasciitis ( $p=0.012)$. Of the 14 patients with mediastinitis, 13 had pleural empyema and 12 had necrotizing fasciitis in the intraoperative findings. However, we must note that the computed odds ratios displayed very wide confidence intervals. The presence of pleural empyema and/or necrotizing fasciitis may not be signs that precede the onset of mediastinitis, but a manifestation of an already established septic mediastinitis, and this should assist in the investigation and in the close monitoring of stable patients.

Our sample showed a $9 \%$ lethality $(n=12)$, with nine patients dying due to infection and three due to non-infectious causes. In the literature, we must separate lethality in patients with necrotizing fasciitis ${ }^{7}$ (13.36\%) due to descending mediastinitis associated with septic shock from the lethality of those who do not have it ${ }^{20,21}$ $(1.4 \%$ to $2.6 \%)$, mainly related to sepsis.

The morbidity of DFSIN is high, especially when there is a complication $5,7,8$. In this study, patients who had complications remained hospitalized, on average, for a period three times longer (27 days) than those without them (8.55 days), with significant difference $(p<0.001)$. In addition, of the 29 complicated patients, 15 underwent two or more surgical procedures. The ICU stay was, on average, 11.7 days, and the mean duration of mechanical ventilation was 7.6 days.

The rapid recognition and treatment of DFSIN are essential for a better prognosis to the patient. Therefore, the identification of morbid factors, signs and symptoms, and the propaedeutics using computed tomography are 
key elements that contribute to better survival results associated with this serious infection.

The recommended treatment we have adopted involves three important pillars: secure airways access (either through endoscopy assistance, or surgically), surgical drainage of involved neck spaces, and clinical and hemodynamic/ventilatory support, with broad-spectrum antibiotic therapy ${ }^{1,2,5}$.

Despite the data analyzed in this series are from a distant period, infections of deep fascial spaces of the neck remain a challenge for the surgeon nowadays, and the diagnostic approach and surgical treatment remain the same, which is why we believe on the validity of our series.

We conclude that the predictive factor of death is the presence of septic shock. The predictive factors for complications are age and the presence of three or more anatomical neck spaces affected by the infection. Necrotizing fasciitis is an important factor for the occurrence of complications and death and, in these cases, surgical approach must be more aggressive. Descending mediastinitis has a high fatality rate, and treatment success is based on early diagnosis and more aggressive surgical approach to this serious condition.

\title{
R E S U M O
}

\begin{abstract}
Objetivo: identificar os fatores preditivos de letalidade e complicações associados às infecções dos espaços fasciais profundos do pescoço, com intuito de estabelecer tratamento mais precoce antes de evolução para a mediastinite. Métodos: estudo retrospectivo de 133 casos, tratados na Disciplina de Cirurgia de Cabeça e Pescoço da Faculdade de Ciências Médicas da Santa Casa de São Paulo. Por meio da análise de regressão logística, estes dados foram estudados para a predição de letalidade e complicações graves (mediastinite, choque séptico, empiema pleural, pneumonia e necrose de pele). Resultados: a taxa de letalidade identificada foi de $9 \%$ e, de complicações de 50,3\%. Identificou-se como fator preditivo de letalidade, a presença de choque séptico $(p<0,001)$ e, para o ocorrência de complicações, a idade $(p=0,017)$ e o acometimento de mais de dois espaços anatômicos $(p<0,001)$. A ocorrência de mediastinite descendente necrosante esteve associada à presença de fasciite necrosante $(p=0,012)$ e empiema pleural $(p<0,001)$. Conclusão: o fator preditivo de letalidade foi a presença de choque séptico e, para ocorrência de complicações graves, a idade e/ou a presença de mais de dois espaços anatômicos acometidos pela infecção. A fasciíte necrosante é fator importante para ocorrência de complicações e morte. Nestes casos, a conduta cirúrgica deve ser mais agressiva. A mediastinite descendente apresenta taxa de letalidade alta e o sucesso no tratamento está no diagnóstico precoce e na intervenção cirúrgica agressiva.
\end{abstract}

Palavras chave: Infecção. Pescoço. Fasciite Necrosante. Mortalidade. Mediastinite.

\section{REFERENCES}

1. Almutairi DM, Alqahtani RM, Alshareef N, Alghamdi YS, Al-Hakami HA, Algarni M. Deep neck space infections: a retrospective study of 183 cases at a Tertiary Hospital. Cureus. 2020;12(2):e6841.

2. Boscolo-Rizzo P, Stellin M, Muzzi E, Mantovani M, Fuson R, Lupato $V$, et al. Deep neck infections: A study of 365 cases highlighting recommendations for management and treatment. Eur Arch Otorhinolaryngol. 2012;269(4):1241-9.

3. Priyamvada S, Motwani G. A study on deep neck space infections. Indian J Otolaryngol Head Neck Surg. 2019;71(Suppl 1):912-7.

4. Barber BR, Dziegielewski PT, Biron VL, Ma A, Seikaly $H$. Factors associated with severe deep neck space infections: Targeting multiple fronts. J Otolaryngol Head Neck Surg. 2014;43(1):35.
5. Prabhu S, Nirmalkumar E. Acute fascial space infections of the neck: 1034 cases in 17 years follow up. Ann Maxillofac Surg. 2019;9(1):118-23.

6. Prado-Calleros HM, Jiménez-Fuentes $E$, JiménezEscobar I. Descending necrotizing mediastinitis: Systematic review on its treatment in the last 6 years, 75 years after its description. Head Neck. 2016;38(Suppl 1):2275-83.

7. Gunaratne DA, Tseros EA, Hasan Z, Kudpaje AS, Suruliraj $A$, Smith $M C$, et al. Cervical necrotizing fasciitis: Systematic review and analysis of 1235 reported cases from the literature. Head Neck. 2018;40(9):2094-102.

8. O'Brien KJ, Snapp KR, Dugan AJ, Westgate PM, Gupta N. Risk factors affecting length of stay in patients with deep neck space infection. Laryngoscope. 2019;doi:10.1002/lary.28367.

9. Velhonoja J, Lääveri $\mathrm{M}$, Soukka T, Irjala H, Kinnunen 
I. Deep neck space infections: an upward trend and changing characteristics. Eur Arch Otorhinolaryngol. 2020;277(3):863-72.

10. Sharma K, Das D, Joshi M, Barman D, Sarma AJ. Deep neck space infections-a study in diabetic population in a Tertiary Care Centre. Indian J Otolaryngol Head Neck Surg. 2018;70(1):22-7.

11. Wang LF, Kuo WR, Tsai SM, Huang KJ. Characterizations of life-threatening deep cervical space infections: a review of one hundred ninety-six cases. Am J Otolaryngol. 2003;24(2):111-7.

12. Marioni G, Castegnaro E, Staffieri C, Rinaldi R, Giacomelli $L$, Boninsegna $M$, et al. Deep neck infection in elderly patients. A single institution experience (2000-2004). Aging Clin Exp Res. 2006;18(2):127-32.

13. McDonnough JA, Ladzekpo DA, Yi I, Bond WR, Ortega G, Kalejaiye AO. Epidemiology and resource utilization of ludwig's angina ED visits in the United States 2006-2014. Laryngoscope. 2019;129(9):2041-4.

14. Huang TT, Tseng FY, Liu TC, Hsu CJ, Chen YS. Deep neck infection in diabetic patients: Comparison of clinical picture and outcomes with nondiabetic patients. Otolaryngol Head Neck Surg. 2005;132(6):943-7.

15. Zheng $L$, Yang $C$, Zhang $W$, Cai X, Kim E, Jiang $B$, et al. Is there association between severe

Received in: 03/03/2020

Accepted for publication: 09/04/2020

Conflict of interest: no.

Funding source: none. multispace infections of the oral maxillofacial region and diabetes mellitus? J Oral Maxillofac Surg. 2012;70(7):1565-72.

16. Pandey AK, Bansal C, Maithani T, Varma A, Singh VP. A Perspective of Clinical Behaviour and Management of Deep Neck Space Infections (DNSI): The Clinical Conundrum. Indian J Otolaryngol Head Neck Surg. 2019;71(Suppl 1):594-604.

17. Zheng $L$, Yang $C$, Kim E, Zhang W, Cai X, Jiang $B$, et al. The clinical features of severe multi-space infections of the head and neck in patients with diabetes mellitus compared to non-diabetic patients. Br J Oral Maxillofac Surg. 2012;50(8):757-61.

18. Bakir S, Tanriverdi MH, Gün R, Yorgancilar $A E$, Yildirim M, Tekbaş $G$, et al. Deep neck space infections: a retrospective review of 173 cases. Am J Otolaryngol. 2012;33(1):56-63.

19. Lee JK, Kim HD, Lim SC. Predisposing factors of complicated deep neck infection: An analysis of 158 cases. Yonsei Med J. 2007;48(1):55-62.

20. Ridder GJ, Technau-Ihling K, Sander A, Boedeker CC. Spectrum and management of deep neck space infections: an 8-year experience of 234 cases. Otolaryngol Head Neck Surg. 2005;133(5):709-14.

21. Wang LF, Tai CF, Kuo WR, Chien CY. Predisposing factors of complicated deep neck infections: 12Year experience at a single institution. J Otolaryngol Head Neck Surg. 2010;39(4):335-41.
Mailing address:

Alexandre Babá Suehara

E-mail: absuehara@gmail.com

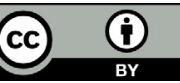

